\title{
EL SINCRETISMO PSICOLÓGICO
}

A pesar que la psicologia es probablemente la más nueva de las ciencias que se ocupan de estudiar al hombre -entendida precisamente como ciencia - cuenta a la fecha con una bibliografía tan abundante que no es igualada en variedad de tratamientos por ninguna otra de las disciplinas que han prosperado con acelerado ritmo en el presente siglo. Recoge una catarata de trabajos que enriquecen continuamente el saber psicológico y enaltecen la noble preocupación del ser humano por conocerse a sí mismo.

Este conocimiento es más urgente mientras mayor sea la evolución del hombre, teniendo en cuenta el gran número de conflictos que han surgido por doquier a consecuencia de su creciente complejidad individual y social, aunada a la inquietud por afrontar de lleno sus problemas y a la angustia por resolver sus graves deficiencias. El deseo expreso del hombre por conocerse objetivamente proviene cuando menos de la antigüedad clá. sica; de ahí la célebre frase de Sócrates: ¡Conócete a ti mismo! Esta inquietud pretende ser ahora despejada por la extensa labor de investigación que manejan psicólogos y antropólogos, pertrechados con mejores armas que nunca para acometer la sugestiva tarea de revelar los recónditos secretos de la existencia y descubrir los ignotos rincones de la personalidad.

En el breve lapso que comprende aproximadamente una centuria, la psicología logró recuperarse del lamentable atraso en que se encontraba por los siglos y milenios de existencia precientífica. Durante ese tiempo se consagró principalmente, en cuanto psicología filosófica, a recoger las creencias mitológicas, religiosas, metafísicas y empíricas sobre el alma en una abigarrada muchedumbre de teorías que, a pesar de todos los intentos, no pudieron resolver a satisfacción este problema. Obviamente, no se disponía de los criterios ni del instrumental necesario para edificar a la psicologia como ciencia. Es sólo hasta el último tercio del siglo xix cuando se descubren las motivaciones determinantes de la conducta y se fijan las normas metodológicas para su tratamiento objetivo y progresivo, esto es, científico.

En tan corto período, el desarrollo de la psicología ha sido torrencialmente pródigo, cual se observa en el crecienta número de instituciones, investigaciones y publicaciones que se le dedican en todo el mundo. Incontables profesionales y una cada vez más abundante bibliografía, dan testimonio de su grandeza y recogen las excelencias de sus mejores frutos.

\section{Las ciencias del hombre}

El vertiginoso desarrollo de la psicología se ha traducido en un acopio [145] 
de datos, experimentos y teorías que cubren básicamente todo lo que pueda exponerse en relación a su problemática, de acuerdo al estado actual de la investigación. Desde luego, la vieja psicología filosófica es puesta en grave predicamento por la moderna psicología científica. Profundiza ella en los temas de la psicología clásica que se refieren a las facultades y la naturaleza del "alma"; afina el método introspectivo como instrumento de la psicología concreta, cuyas observaciones sobre la conducta son esenciales al conocimiento del Yo; ha puesto de lado los prejuicios que aherrojaban al saber psicológico en los grilletes del fanatismo y la ignorancia. Ahora se determinan experimentalmente multitud de fenómenos parapsicológicos que permanecían inexplicados ante la antigua ciencia y se tratan minuciosamente las cuestiones dinámicas del comportamiento, extendiendo los alcances de la psicología científica al campo biológico y al cultural.

La gran cantidad de temas que maneja actualmente la psicología cientifica despeja al máximo el horizonte para producir un estudio sistemático, que es tanto más difícil de obtener por cuanto reclama una extensa documentación en multitud de cuestiones especificas pertenecientes al vasto conjunto de disciplinas que integran el complejo de las ciencias del hombre, el cual abarca el territorio más amplio y en cierto modo el más valioso de todos los que pueda cubrir el intelecto; consideramos que el conocimiento más importante es el del hombre y en mayor o menor grado cualquier ciencia admite una jurisdicción aplicable al conocimiento del hombre.

Sin embargo, el inconveniente relativo a esta intrincada complejidad del saber es la confusión de sus diversas parcelas, que deben acotarse en la jurisdicción que corresponde a cada una y en las interrelaciones que forzosamente establecen todas ellas. Sobre ese punto descansa la problemática crítica de la psicología científica; no estriba en la carencia de conocimientos, sino tal vez en el exceso y la confusión de los mismos, que repercute en cierta parcialidad displinaria y en un evidente antagonismo, no sólo de sus doctrinas, sino de quienes las defienden. Una divergencia natural en campos diversos del saber, tradúcese a incomprensión y negación de los fueros disciplinarios, llegando finalmente a manifestarse en antagonismo y tal vez abierta enemistad de sus cultivadores. ¡La ciencia de lo racional incurre en su propia negación; la psicología y los psicólogos se vuelven en esta tessitura absurdamente irracionales!

Con el propósito de contribuir a despejar esta borrosa perspectiva, nos proponemos ensayar una breve exposición y clasificación de los grandes planteamientos psicológicos, agrupándolos en sus doctrinas o escuelas fundamen: tales y observando los rasgos de cada una para extraer su problemática esencial y delinear un examen comparativo de sus tendencias, doctrinas, direcciones, escuelas o vertientes y concluir en la importancia peculiar que pueda tener cada una para el conocimiento del hombre, así como su común 
posibilidad integrativa, situadas como se encuentran todas ellas en el abigarrado panorama contemporáneo de esta importantísima y apasionante investigación humanista.

\section{Psicologia y psicologias}

El punto de partida en este ensayo está representado por el núcleo de las principales tesis que alimentan a la ciencia psicológica y que, en último término, es solamente una; todos sus problemas corresponden al tema básico que se expresa en la siguiente pregunta: ¿Qué es el hombre? $\mathrm{O}$, para precisar: ¿Qué son la conciencia y la conducta del hombre? Los tratamientos diferenciales que genera este problema se han desenvuelto a un grado suficiente para considerarlos como direcciones autónomas de la psicología; en cada una de ellas se agrupan numerosos pensadores inquietos por un problema común: el conocimiento del ser humano y la explicación de su conducta.

Al ingresar en este dominio epistémico tropezamos con varias doctrinas que obedecen a planteamientos distintos y evolucionan conforme a métodos diferentes. Cada una parece no sólo diversa sino irreductible a las demás; todas ellas ostentan el mismo título: psicologia. La inevitable sugerencia motivada por este pluralismo doctrinario es que no hay una sino varias psicologías.

Ahora bien, se puede hablar en cierto modo de psicologia y psicologias, siempre y cuando se mantenga en ellas una relación similar a la que existe, por ejemplo, entre la física y las diferentes ramas de la física. Así como en ella un capitulo de mecánica figura junto a uno de óptica, otro más de ter modinámica, electromagnética, etc., pueden coexistir con la misma congruencia las distintas parcelas que configuran el territorio de la psicología y que habitualmente se toman como corrientes, escuelas, posturas, direcciones, vertientes, ramales o ciencias psicológicas distintas.

\section{Afluencia y confluencia}

Para comprender el por qué de las grandes direcciones que asume la psicología en su trayectoria evolutiva y su integración sistemática, será menester excogitar, cuando menos en lineamientos generales, el papel que desempeña cada una en el común propósito de explicar el funcionamiento de la conciencia y el sentido de la conducta del hombre. Para ello será indispensable pasar revista a los afluentes que recibe nuestra disciplina según el problema que admite en cada caso y el método que utiliza para resolverlo; apuntaremos finalmente a la confluencia de dichas doctrinas en el sistema unitario, dialéctico y sincrético de la psicología. Tal es la perspectiva 
que encontramos al iniciar nuestra breve incursión en la problemática psicológica y, después de contemplarla panorámicamente, diseñaremos el primero de sus bocetos, que nos informará sobre la dificultad de establecer un concepto básico de esta ciencia.

El primer problema que acometeremos será formular una correcta definición de la psicología, lo cual implica, como base, precisar el contorno de su objeto, condición indispensable para establecer el alcance, las limitaciones y la orientación general del método que lo desarrolla. En caso contrario se cae en el grave riesgo de extraviar sus principios, esfumar sus límites y confundir sus procedimientos. Esto es lo que sucede en la mayoría de las veces; como hemos dicho, la psicología registra una gran variedad de acepciones por las cuales muy difícil es caracterizarla en forma unívoca y rigurosa.

Observada históricamente, priva de una época a otra divergencia tal en problemas y métodos de trabajo, que el nombre de psicologia viene a quedar casi en calidad de un mero nombre, al punto de que inclusive el profesional en la materia suele tener dificultades para orientarse en la urdimbre de prospectos que se ofrecen a su tratamiento.

El mayor obstáculo para captar de conjunto el panorama de la psicología se encuentra en la creciente especialización que asiste a sus diferentes doctrinas, las cuales se han llegado a difundir y confundir profusamente. El psiquismo es para unos la entidad inmaterial que refiere la vieja metafísica, mientras para otros - la gran mayoría - representa una realidad concreta, asequible por un medio experimental y determinada por su función en la naturaleza. El hombre puede modificarla mediante ciertas técnicas que propician su desarrollo; el psiquismo es una entidad plástica y maleable, inmersa en la experiencia y susceptible de cambiar notablemente con el impulso formativo de la educación.

Entre ambas posiciones, la que sostiene' al "alma" como una entidad metafísica y absoluta, y la que afirma su materialidad evolutiva, hay un gran número de matices intermedios que representan sendas etapas en el desarróllo científico de la psicología. A través del tiempo se ha hecho radical diferencia entre el tratamiento que recibe el psiquismo en la escuela tradicional y el que le otorgan sus direcciones modernas.

\section{Complejidad y especialidad}

La abundancia de las manifestaciones psicológicas explica la insólita complejidad de esta ciencia, cuyo panorama se complica con las esferas de influencia que admiten recíprocamente los hechos psicológicos. Sabemos que la conducta es muy variable y compleja; sus manifestaciones no se producen aisladas, sino en estrecho vínculo con la compacta estructura donde se entrelazan las numerosas expresiones culturales, que son expresiones de la con- 
ciencia individual y colectiva. Es comprensible que, en medio de esta situación, existan divergencias de criterio para establecer el método y el problema en cada una de las teorías que se encuentran a cada paso de su desarrollo.

El proceso histórico que ha operado en el campo de la psicología es análogo al que observamos en las demás ciencias; tiene de común con ellas la creciente especialización en sus tratamientos. Este hecho obedece a la constante diversificación en sus problemas y sus métodos, a la agudizada singularidad de las manifestaciones psíquicas, a la compleja extensión en el tratamiento de cada tema, lo cual hace más difícil la compenetración de la psicología y prácticamente imposible dominarla a satisfacción en toda su amplitud disciplinaria.

El proceso de la especialidad llega a todas las formas del saber; puede expresarse diciendo que predomina la tendencia a conocer cada vez más sobre cada vez menos o, lo que equivale, a obtener un mayor número de conocimientos en un menor campo de observaciones. La especialización de los estudios afecta notablemente a la formación de profesionales que suelen ignorar el alcance total de esta ciencia y, en el mejor de los casos, conocen una sola de sus ramas. Esta es obviamente una desventaja por cuanto fomenta el soslayo de los temas diferentes a los que se cultivan, pero al mismo tiempo permite el gran avance de la especialización profesional, con el impulso que otorga al saber en el dominio de las cuestiones específicamente tratadas en cada disciplina y en cada una de sus ramificaciones.

No existen actualmente profesionales que dominen todas las tendencias de la psicología; lo más a que pueden aspirar es al conocimiento de una sola, si quieren realmente estar enterados de ella. La posibilidad de ir al dia en los progresos que lleva a cabo la ciencia en cualquiera de sus ramas, absorberá todo el tiempo que pueda dedicarle el más tenaz de los estudiosos. Pero la desventaja de la especialidad comporta una gran ventaja, consistente en penetrar cada vez más en el mundo individual de los problemas y obtener conocimientos cada día más profundos sobre una misma disciplina.

Gracias a esta incesante especialización han progresado insospechadamente las ciencias; sus enfoques se hacen más profundos a medida que se contempla un menor campo de acción y se cala más hondo en su problemática. Sin embargo, el gran inconveniente es que, al ignorar lo que sucede en otras ramas del saber, aparece la inevitable incomprensión frente a los sistemas que manejan otros especialistas; la incomprensión en los sistemas origina la incomprensión en las personas y surge de ahí el nocivo antagonismo que se observa entre los cultivadores de una ciencia, por el solo hecho de pertenecer a especialidades distintas.

El gran número de especialidades producidas en la psicología obedece también a la diversificación de los hechos psíquicos, cuyas interconexiones hacen que su problemática se manifieste con insospechada complejidad. Es 
indispensable tener en cuenta esta dinámica pues si no se admite previamente la complejidad de los problemas psíquicos se caerá en el riesgo de permanecer limitado a una sola orientación, circunscrito a un mismo tipo de problemas, ignorando la multitud de factores e interrelaciones que acoge continuamente el psiquismo; si alguno de esos factores queda insuficientemente comprendido, las interrelaciones concomitantes tendrán que sufrir también un sensible deterioro en su comprensión científica.

Concluimos, pues, que la deficiencia de entendimiento común que se manifiesta en la gran mayoría de las posturas psicológicas, deriva en gran medida de la creciente especialidad que hemos señalado y como consecuencia inevitable del particularismo con que se abordan los trabajos de investigación psicológica, en paralelo al funcionamiento estructural que caracteriza a la ciencia contemporánea. Con esta observación llegamos al punto medular de nuestro ensayo, cuyo propósito consiste en señalar la diversificación doctrinaria de la psicología para bocetar una exposición de sus temas esenciales, exhibiéndolos con el enfoque general de la unidad sincrética que les corresponde en cuanto derivados de una sola ciencia, la psicología, y, por consiguiente, copartícipes de la radial unidad temática que se distribuye en los tratamientos aporéticos y en las normas metodológicas específicas; con ello, la unidad no desaparece, al contrario, se refuerza en la medida que una pluralidad epistémica se unifica alrededor del eje que determina el problema constitutivo de la disciplina fundamental.

Esta prospección es indispensable para captar la imagen conjunta de la psicología moderna. Mencionaremos a continuación las principales especialidades que corresponden a sendas orientaciones básicas de dicha cienciạ. Lo más importante de su temática será comprender que todas las ramificaciones se unifican en la integración del sistema psicológico y cuyos grandes afluentes desembocan en el interés común de alimentar en todo lo posible el caudal del conocimiento sobre el ser humano.

Lo más importante de todo es que en esta época la psicología ha logrado definitivamente su consolidación como ciencia, con el tratamiento múltiple y correlativo de sus problemas, acompañando en cada caso el método respectivo y produciendo finalmente el gran sistema que los unifica de manera virtual y formal en una suprema unidad doctrinaria.

\section{Direcciones y posturas}

La conclusión que acabamos de exponer indica que el estudio de la psicología es abordable mediante el examen de las grandes vertientes que se manifiestan como direcciones fundamentales de la psicología, con la derivación que adquieren en las escuelas y posturas donde se desenvuelven por efecto de la inherente particularidad de sus planteamientos. Este diorama de estudio se encuentra en todas las ramas del psiquismo; cada una produce 
la respectiva especialización del saber, partiendo en todo caso del planteamiento señalado por la pregunta general, que formulamos de la siguiente manera: ¿Qué es y cómo actúa la conciencia?

A partir de esa cuestión básica se desenvuelven las diversas especialidades que corresponden a maneras diferenciales de entender el ser consciente como denominador común en todas las expresiones de la psicologia científica. La evolución de sus grandes direcciones ha dado origen à sendos capítulos constitutivos que obedecen a la postulación de sus problemas capitales y corresponden a los aspectos o funciones que presenta el objeto primordial de esta ciencia, la conducta humana, explicada mediante el estudio analítico de la conciencia. Nos interesa subrayar una vez más que la relación metodológica en cada uno de los grandes problemas y la respectiva especialidad profesional, explica la génesis de las corrientes, direcciones, escuelas o tendencias psicológicas, derivadas de los parámetros parciales del problema que se debate; en otras palabras, corresponden a maneras diferentes de captar y entender un problema básico: la conciencia, cuya manifestación externa es la conducta.

Cada una de las grandes ramas psicológicas da origen a nuevas especialidades que alcanzan un nivel de mayor particularidad a medida que el saber avanza en el estudio de los fenómenos concretos y percibe directamente la realidad del problema en la consideración del sector psicológico respectivo. Los 'estudios pueden efectuarse en diversos grados de particularidad o generalidad, según el problema, desde los casos singulares de cada individuo hasta las teorías más generales en que se basa el criterio de valoración para los síntomás y testimonios de diversa índole, incluyendo las pruebas analíticas que ófrecen una norma criteriológica y las pautas estadísticas, que son también notas de referencia para indagar la posibilidad de incluir en la pesquisa no sólo casos concretos, sino encuadres comparativos donde se apoyan las estimaciones de cantidad que por si mismas resultan inexpresivas cuando no les acompaña una referencia homóloga de normatividad axiológica.

Los puntos concluyentes de esta observación preliminar informan que existen en la psicología, igual que en toda ciencia, tres dimensiones aporéticas que orientan su evolución.

a) Problema esencial. Planteamiento que corresponde genéricamente a todos los problemas y tratamientos que asume el desarrollo de una disciplina científica, en este caso, la psicología.

b) Problemas generales. Diferentes maneras que tiene el problema esencial de manifestarse ante la consideración primaria de las grandes direcciones particulares que lo manejan.

c) Problemas especiales. Surgen con el tratamiento de las cuestiones concretas y tienden a lo singular, a medida que se aproximan a la individualidad de la experiencia. 
Esta integración del saber en tres grandes niveles aporéticos se comprueba en todas las ciencias, que precisamente por serlo dan origen al variable contorno problemático y la correspondiente forma metodológica con la cual se construye el cuerpo sistemático de la psicología. Recíprocamente, la especialización de los conocimientos a partir del planteamiento general, diseña la disposición arborescente que genera el sistema de acción y evolución en cada disciplina.

\section{La integración cientifica}

Recordemos que las demás ciencias han proseguido un camino similar a la psicología, partiendo inicialmente de un planteamiento genérico y un tanto indeterminado, para definirse paulatinamente por el camino de la especialidad, llegando a la unidad sincrética del tema original en la disposición arborescente que recoge todas sus ramas particulares, desde la concreción individual de la experiencia, que simbolizan las ramificaciones últimas de la disciplina, hasta el tronco principal donde nacen todas ellas porque contiene el tema básico de cada disciplina. En nuestro caso, dicho tema es la conciencia.

Así sucedió con la física, entendida en la antigüedad a título indeterminado de ciencia de la naturaleza y proliferada más tarde en numerosas especialidades que ahora han recogido las ciencias naturales; y que, después de una prolongada etapa en la cual se mantuvieron aisladas, vuelven a reintegrar su unidad en el concepto de naturaleza mediante la reconstrucción integral del sistema, que obviamente se produce a partir de los logros obtenidos por cada una de tales ciencias. De este modo se cumple el ciclo evolutivo en un complejo epistémico: nace de la matriz formal que recoge el enunciado más amplio del problema, se multiplica paulatinamente en ciencias independientes y afines, para reintegrarse por último a la unidad formal y sincrética del sistema, contando con los aportes materiales y las determinaciones concretas de cada rama experiencial.

En este ciclo representa un papel muy importante la filosofía, cuyo significado varía notablemente del punto de partida, cuando se confunde con la ciencia misma, al de llegada, cuando vuelve a ser "filosofía" a la manera de ciencia formal-metodológica y unidad coordinadora del sistema. El mismo ciclo se observa en la sociología, como sistema de las ciencias sociales; en la antropología es sistema de las ciencias del hombre; las matemáticas integran un sistema autónomo pero se relaciona con todas las ciencias. $\mathrm{Y}$ así sucesivamente.

Llegará un momento en que este ciclo se cumpla en las disciplinas psicológicas, cuando hayan alcanzado tal madurez en su crecimiento autónomo, que no pueda hablarse indeterminadamente de la psicología, cuyo nombre 
conviene a tantas modalidades de un saber homólogo, que el vocablo en sí mismo resulta indiferenciado $y$, por ende, inexpresivo. Estamos llegando a situación tal porque las ramas de la psicología se han diversificado ahora hasta al punto de quedar divorciadas, cuando menos en apariencia, y sus cultivadores resienten este divorcio en forma de un antagonismo que repercute nocivamente para la comprensión integral de la disciplina, en vez de adaptarse a un criterio común, no obstante la preparación que tienen los profesionales en cada una de sus ramas, o precisamente por ella.

A través de este ciclo dialéctico se comprende la evolución de la psicología frente y al lado de los demás complejos disciplinarios; se trata, en suma, de la ubicación inicial del planteamiento originado en el ámbito filosófico, donde en cierto modo se han incubado todas las modalidades del saber en una primera etapa desintegrativa que abre la puerta a la erección paulatina de las "ciencias particulares". Estas se diversifican en aras de la especialización a medida que penetran en su problema y finalmente rebuscan la unidad integral del sistema y la construyen como una nueva expresión de la filosofía, o si se quiere, como expresión de una nueva filosofía. Esto es lo que ocurre actualmente en la psicología sincrética y en la antropología formal, así como en todo el ámbito de las ciencias del hombre.

\section{El problema psicológico}

Lo que hemos dicho sobre el problema psicológico refrenda la dinámica que en términos generales expone la evolución histórica del pensamiento. Es, sin embargo, uno de los casos más evidentes donde se aprecia la disposición flabeliforme que adquiere el sistema cognoscitivo de acuerdo a la creciente especialización y la concomitante complejidad que asumen sus investigaciones. En la ciencia que nos ocupa existe un problema general que obedece a una misma realidad aporética y dialéctica, como es el funcionamiento interconsciente del psiquismo. Esta dialéctica constituye el correlato de las vinculaciones temáticas y metodológicas que pueden establecerse en las relaciones intersectoriales de la psicología, pues al ser la proyección consciente por excelencia dialéctica, tiene que serlo paralelamente la disciplina que la explica.

De ahí se observa la construcción de una psicología sintética, unitaria, vinculatoria o, como la llamamos nosotros, sincrética: creemos que la psicología sincrética es la psicología por excelencia, la única disciplina con el único método capaz de explicar en forma dinámica las operaciones profundas del psiquismo, que son también las más complejas, las que reúnen el mayor número - por no decir la totalidad- de los coeficientes que determinan al psiquismo y la conducta, o sean la conciencia e interconciencia individual y colectiva. Sobre lo que última instancia deban ser la conducta y el psiquismo, existen multitud de teorías, desde las que optan por una función 
biológica y material, hasta las muy tradicionales que proclaman en el hombre las virtudes prístinas de la espiritualidad, llegando a la inconsútil esfera de la metafísica, la mística y la religión.

A pesar de ello, existe un acuerdo básico al afirmar la existencia de psiquismo e interpsiquismo, externado fundamentalmente en la acción dinámica de la conciencia, que viene a ser también interconciencia. Entendemos al funcionamiento interconsciente como la manifestación más elevada de la naturaleza humana, y más allá de las divergencias que derivan de la introspección individual, aparece el criterio distintivo de lo psicológico, el consenso unánime de la vida consciente, interconsciente y paraconsciente, que constituye la expresión superior, la más auténtica y genuina del hombre.

A partir de este acuerdo fundamental se erigen las grandes direcciones de la psicologia, teniendo como principio histórico la psicología precientífica y como base la que llamamos precisamente psicología básica, o sea la ciencia explicativa de los fenómenos conscientes a nivel elemental o epidérmico que comporta la descripción de dichos fenómenos. La totalidad de las doctrinas psicológicas está de acuerdo en admitir que la manifestación fenoménica del psiquismo está cifrada en términos de conciencia, aunque ella debe ser entendida en la amplia acepción que le hemos dado como interconciencia. Puede haber disentimientos, y los hay bastante agudos, en el desarrollo de las posturas, pero la unidad básica en cada disciplina está fundada sobre el acuerdo de que la acción consciente es lo netamente humano, por lo cual se considera a la psicología básica, explícita o explícitamente, como ciencia de la conciencia.

El antecedente histórico de la psicología básica, que debe considerarse como precursión de todas las modalidades cientificas de esta disciplina, es precisamente la que denominamos en términos generales psicología precientifica, entendiendo por tal no sólo la que precede cronológicamente a la constitución científica de la psicología, sino en términos más amplios, cualesquiera expresiones de un conocimiento elemental sobre el psiquismo y la conducta, que suele quedar cifrado en términos de alma o espíritu, y canalizado en su mayor volumen a teorías metafísicas por conducto de la filosofía y la religión, así como la síntesis que en cierto modo constituye la psicofilosofía religiosa. La gran mayoría, cuando no la totalidad de las doctrinas filosóficas sobre el alma o el espíritu, debe considerarse perteneciente a este sector de la psicología precientífica, que se distingue evidentemente de la psicología científica propiamente dicha y en nuestro tiempo resulta inasimilable con ella.

El horizonte psicológico se extiende constantemente al tratamiento de algunos problemas que colindan con la conciencia e implican factores que se relacionan, pero no se identifican con ella. De manera principal, las funciones somáticas que estudia la psicologia biológica al examinar los sistemas 
que dependen del organismo físico, tales como el equilibrio metabólico, la generación hormonal, los mecanismos cerebrales, los sistemas musculares, y muchos otros que configuran la vida fisiológica, distinguible de la netamente psicológica, aunque influye decisivamente en su desenvolvimiento.

También el tratamiento del inconsciente, o como le llamamos nosotros, el interconsciente, se consagra en el psicoanálisis y configura una doctrina de la mayor importancia cuyo sistema corresponde estudiar a la psicología analitica; esta ciencia ha venido a enseñar, como un método especifico, que no todo en el psiquismo es absolutamente consciente; no nos damos cuenta integra de nuestros actos porque gran parte de ellas están determinados por motivaciones subconscientes o paraconscientes, que configuran con la conciencia propiamente dicha, el complejo sistema de acción y reacción psíquica que es el interconsciente.

Por otra parte, la interacción de los individuos tiene lugar en el seno de la colectividad; éste es otro de los determinantes irremplazables de la conducta. Todos nuestros propósitos están matizados en gran medida por las circunstancias que nos rodean desde el nacimiento, y virtualmente desde antes, ya que la influencia del medio social es ejercida incluso en la gestación y termina hasta el instante de la muerte. Este es, quizá, uno de los factores más decisivos y de los que menos se percata el individuo, porque la modelación ejercida por la sociedad se convierte en una especie de "segunda naturaleza" paraconsciente, que a veces llega a ser la primera. De ahí la abundante problemática generada por la interdeterminación de los factores sociológicos y los psicológicos, que motiva su confluencia en otra gran vertiente disciplinaria como es la psicología social.

Por último, la psicología se ha enriquecido notablemente con la admisión académica de los estudios que tratan de elucidar un tipo de fenómenos que hasta hace poco se consideraban "sobrenaturales" y, por consiguiente, inexplicables. Por ejemplo, el hipnotismo, la clarividencia, la teleaudiencia, el desdoblamiento, la telepatía, la telequinesia y muchos otros que se examinan ahora sobre bases estrictamente científicas, obteniendo resultados cuya acumulación constituye una nueva disciplina que se ubica al lado de la psicología, por cuya razón denomínase parapsicologia; es, en efecto, una ciencia que debe estar en la psicologia, aunque todavía se le considera distinta de ella. Pero es evidente que en poco tiempo formará parte integrante de la psicología misma y sus rendimientos servirán no sólo para explicar los fenómenos que ahora le preocupan, sino otros más que se descubrirán paulatinamente; los signos más elocuentes en este género de investigaciones indican que se trata de un vasto mundo hasta ahora desconocido para la ciencia oficial, aunque sus testimonios originales provienen de la antigüedad.

Hemos perfilado cuáles son las grandes orientaciones de la psicología, tal como se integra actualmente, correspondiendo a sendos planteamientos en el 
tema de la conciencia y contemplados desde el ángulo que corresponde a cada una, según queda precisado en la breve referencia que damos a continuación:

a) Psicologia precientifica. Son las concepciones sobre el alma anteriores al estudio científico del psiquismo y la conducta y se dan principalmente en la filosofía y la religión.

b) Psicologia básica. Reconoce en la ciencia la manifestación psicológica del individuo y adopta como punto de partida el ejercicio normal de sus facultades.

c) Psicología biológica. Señala principalmente los factores biofísicos como determinantes de la conciencia y la conducta; desemboca en un materialismo naturalista.

d) Psicologia analítica. Admite la acción del inconsciente y el interconsciente como definitivo en la actividad normal y patológica de la conducta.

e) Psicologia social. Investiga las relaciones entre la conciencia personal y el comportamiento colectivo, partiendo de su mutua influencia en la realidad.

f) Psicologia parafísica. Estudia fenómenos reales, pero extraños, cuya explicación no se ha otorgado plenamente, aunque se investigan mediante el funcionamiento de la paraconciencia.

Seguiremos el propósito que nos hemos trazado, diciendo algunas palabras relativas a cada una de esas direcciones fundamentales de la psicología.

\section{a) La psicologia precientifica}

La complejidad del problema psicológico se manifiesta en la prolongada integración histórica de la psicología, que ha debido partir desde el estado mitológico y metafísico en que se encontró durante la prolongada época en la cual se mantuvo ajena a la cientificidad, hasta llegar al apreciable grado de adelanto que se comprueba actualmente, cuando su problemática es debatida con criterios mucho más sólidos que los que fueron usados en su anterior edad.

Dos son los grandes enfoques que permiten abordar a la psicología en la forma estructural y sincrética que reclama el conocimiento de la ciencia; uno de ellos corresponde a la integración histórica de la psicología, perseguida a partir de las primeras etapas en que se encontraba situada en el tronco de la filosoffa especulativa, como también de la teología y la religión, pues la inquietud por saber cuál es la esencia y consistencia del alma ha sido una de las más antiguas que experimentó la humanidad. En semejante estado de precientificidad transcurrieron durante mucho tiempo las ideas psicológicas, cuyo carácter extendiose por veinticinco siglos debido a la gran dificultad para construir una auténtica psicologia científica, la cual -como es 
bien sabido- logró integrarse hasta la época moderna, después de que sus principios y métodos de trabajo se hubieron radicalmente transformado.

Antes de que el pensamiento psicológico se pudiera configurar en ideas elementales como fueron las primeras de la filosofía, precientificas pero al fin de cuentas racionales, imperó un concepto irracional del alma, que tuvo como primera manifestación la creencia en poderes sobrenaturales que existirían antes de la creación del hombre y la naturaleza, acentuándose esta creencia en la imagen de un Dios omnipotente, creador del hombre y del universo. Aún la creencia religiosa en el espíritu no ha desaparecido, desde el momento que subsiste como parte constitutiva de las religiones que abraza la inmensa mayoría de la humanidad. De acuerdo con esta idea general, Dios creó al hombre $y$, por consiguiente, a su conciencia. La explicación de por qué tuvo lugar tan soberano acto, varía de acuerdo a las diferentes religiones, pero la creencia fundamental en el Dios creador y el hombre creado, subsiste incólume como esencia de todas las religiones.

El criterio de la religión imperó y sigue imperando como creencia acientífica y netamente dogmática; tiene como fundamento genérico la dualidad de alma y cuerpo, que se supone mantienen un determinado paralelismo psicofísico en cuya virtud los fenómenos anímicos acontecen dentro del cuerpo y guardan una estrecha relación con él, mientras transcurre esta vida mundana en la que se encuentra el alma confinada a la cárcel corporal, por supuestos motivos que cada religión expone a su manera.

A medida que transcurre el tiempo, resulta cada vez más difícil conciliar las ideas religiosas con la psicobiología científica, que hasta ahora ha demostrado satisfactoriamente cómo se efectúa la paulatina integración del ser, e incluso efectúa penetrantes estudios en la vida prenatal, dificultando en alto grado la adaptación de las teorías religiosas para explicar este proceso. Sin embargo, no han desaparecido las creencias dogmáticas de carácter acientífico que pretenden explicar la creación del hombre recurriendo a la imagen de Dios, quien en ejercicio de su soberana voluntad se dignó crear al hombre y al universo "para su mayor gloria y exaltación".

\section{b) La psicologia básica}

El punto de partida que adoptamos para apoyar la definición de la psicología como ciencia de la conciencia, está contenido implícita y explícitamente en los problemas que maneja. El concepto básico de psicología tiene como objeto tradicional examinar las diversas formas y modalidades que asume la conciencia en el ejercicio de sus facultades.

Esta vertiente tradicional de la psicología se dirige al contorno fenoménico de la conducta, percibida introspectivamente por el sujeto que la observa y reflejada extrospectivamente en los demás. Las nociones que proporcio- 
na la introspección complementan la referencia directa o indirecta que obtiene por el método extrospectivo, llegando a un apreciable grado de objetividad en sus observaciones y en la explicación de los fenómenos que contempla.

El punto de partida que adopta la psicología tradicional consiste en concebir la estructura de las facultades perceptivas como base para construir el sistema, que se podría denominar epidérmico, quizá parcial o elemental, pero subsistente en sí mismo. Las observaciones efectuadas desde la antigüedad sobre el funcionamiento de la conciencia revelan cuál es y cómo se verifica la acción de las facultades que siguen operando en la conducta y constituyen la base para una explicación ulterior, mediante sistemas que inciden en las estructuras: básica, biológica, analítica, sociológica y parafísica. En ellas siguen siendo esenciales: la percepción, la sensación, la representación, la imaginación, el razonamiento, la voluntad, los sentimientos, la memoria, la asociación, etc., facultades todas ellas que descubrió la psicología clásica, aunque su tratamiento sea mucho más dinámico en la moderna, que es por excelencia una psicología estructural. Las observaciones de la psicología clásica, que nosotros denominamos funcionalmente básica, aportan los elementos del sistema sincrético para las grandes funciones o estructuras que se constituyen en los sistemas señalados hace un momento: básico, biológico, analítico, sociológico y parafísico.

Lo que nos interesa resaltar en este caso es la existencia de una psicología clásica que desempeña la función pertinente a las posiciones, también clásicas, que se encuentran en las demás ciencias. La importancia del señalamiento estriba en que no deben desecharse las doctrinas que se entienden como clásicas por el solo hecho de haber sido superadas con el advenimiento de la ciencia moderna, antes bien, sirven aquéllas de base para el desarrollo ulterior de esta disciplina.

Existe el prejuicio muy extendido de que una tesis cualquiera, al ser superada por otra, debe arrojarse inmediatamente por la borda, cuando en verdad dicha superación equivale en cierto modo a su consagración permanente, desde el momento que la superación misma es posible por y sobre la base que proporcionan las observaciones primordiales en toda doctrina científica. Tal superación y el consiguiente arribo a nuevos estados epistémicos no se lograría sin el basamento que proporcionan las deducciones primarias en torno a las facultades psicológicas, de donde la necesidad de conservar el desplante arquitectónico de esta ciencia y mantener sus aportaciones como punto de partida indispensable en la erección estructural de la psicología moderna.

La base del gran sistema que integran todas las vertientes de la psicología estriba en los procesos que refiere la psicología clásica a partir de las "facultades del alma", interpretadas en forma mucho más profunda y dinámica por las actuales concepciones de esta ciencia. Pero los procesos y las 
facultades subsisten en actos tan fundamentales como la sensación, la percepción, la representación, la imaginación, la memoria, etc., que representan en cierto modo el punto de partida o sea el problema por explicar, en las escuelas contemporáneas de esta disciplina.

El planteamiento que hizo posible la psicología clásica, tradicional o básica, pues los hechos que estudia constituyen la base del psiquismo, radica en sus principios aporéticos, que han sido también la base de ulteriores desarrollos. La fuente documental es predominantemente introspectiva; se dirige inicialmente a la observación del Yo como es percibido por el sujeto, y sólo después acude a referencias externas o extrospectivas, que complementan a las introspectivas. El sistema se ha convertido a lo largo de veinticinco siglos en una tradición clasicista, impartida oficialmente como enseñanza académica; en tal condición se mantuvo desde la antigüedad hasta principios del siglo $\mathrm{xx}$, cuando nuevos horizontes abrieron el estudio psicológico más allá de las fronteras a las que había llegado la tradición. Actualmente la psicología clásica es de todo punto insuficiente, mas no por ello se descartan sus postulados, sino se relativizan en su ámbito de valor como producto de un método específico. Es el producto del examen que el sujeto efectúa en sí mismo para inducir las generalidades que expresan empíricamente a la fenomicidad psíquica.

He aquí, pues, la segunda de las grandes direcciones que observamos en este prospecto, la psicologia básica, cuyas características han quedado someramente descritas. Por su conducto se establecen las primeras ideas generales en torno al psiquismo; sus elementos constitutivos reciben el nombre de facultades del alma, virtudes anímicas o atributos espirituales, cual se designan a las que son en verdad funciones psicológicas: la sensación, la percepción, la representación, la imaginación, la memoria, el razonamiento, la voluntad, el sentimiento, etc., que todavía en la actualidad constituyen un importantísimo objeto de estudio y ocupan el umbral para transitar ulteriormente por toda la ciencia psicológica. De ahí el evidente carácter básico que exhibe esta dirección y el nombre que justificadamente le atribuimos.

\section{c) La psicología biológica}

La tercera de las grandes vertientes psicológicas está constituida por otro de los determinantes fundamentales del psiquismo, a saber: la influencia que recibe de la naturaleza biológica, entendida mediante el análisis del comportamiento y sobre el plano que ocupan las ciencias naturales. Dicho análisis culmina en la constitución biológica del individuo, o sea el organismo físico que sirve de sustento a la organización psíquica, la cual es determinable en su estructura material, principalmente en el superior estrato de la vida humana, tal como se traduce y expone en la actuación interconsciente. 
Quienes defienden la tesis de que el ser humano es íntegramente una entidad material, despliegan sus esfuerzos para comprobarla mediante un estudio cada vez más penetrante de los fenómenos biológicos que acompañan a la actividad psíquica. Los partidarios radicales de esta teoría sostienen que las funciones fisiológicas, y quizá sólo ellas, intervienen para determinar, y por consiguiente explicar, a la conciencia y el comportamiento. Esta es la interpretación que debe otorgársele para ser fieles a la postura materialista que expresa dicha teoría.

Como la materialiadad del hombre se manifiesta a través de la organización biológica, resulta de ahí que la psicología naturalista y materialista se constituye en una psicología biológica, cuyo basamento científico está apoyado por todas las disciplinas que integran el sistema de las ciencias naturales; la suma de conocimientos y el rigor en los métodos de experimentación que encontramos en esta corriente, aporta sugerentes elementos de juicio para incitar en un momento dado a canalizar por su conducto el problema de la psicología. Esto es lo que se observa en la escuela materialista, que es quizá mayoritaria en nuestra época e irrumpe con creciente intensidad en la psicología moderna.

En apoyo de tal vertiente acuden no sólo las ciencias biológicas en general, sino específicamente las ciencias médicas y antropológicas; también el vasto complejo de las ciencia físicas, e inclusive las matemáticas, adquieren una poderosa intervención en su desarrollo. La categoría de ser vivo que posee el hombre lo ubica en el campo de observación de las ciencias que estudian a la naturaleza material; se interpreta en ellas la acción de la conciencia como si fuera un organismo biológico, es decir, como si fuese íntegramente explicable en función de leyes biológicas; ésa es la motivación radical en tan importante escuela de la psicología contemporánea.

Ocupa un lugar destacado en el seno de esta psicología científica, la doctrina de los reflejos fisiológicos que estudió Ivan Pavlov, cuya doctrina se dedica también al estudio psicofisiológico de la conducta, pero deriva su atención a las formas reactivas que son determinadas por el mecanismo de los reflejos condicionados. A partir de este principio, la teoría pavloviana pretende integrar todo un sistema de psicología conductista examinando formas cada vez más complejas de asociación refleja en una especie de axiomatización psicofísica de la conducta que establece las relaciones biológicas a partir del determinante fisiológico en el campo de las coordenadas asociativas.

Ahora bien, con independencia del crédito que se le conceda en el terreno de la fisiología, esta corriente es muy controvertible en cuanto sistema psicológico; ha asumido una gran importancia la difusión doctrinaria por el hecho, nada científico en sí mismo, de haberse adoptado como doctrina oficial, e impuesto como la única posible para acometer los problemas de la 
psicología, en algunos paises socialistas que profesan la "fe científica" del marxismo: obviamente, en primer término la Unión Soviética. Quizá. este hecho, más aún que su aporte a la psicología propiamente dicha, es lo que ha dado mayor beligerancia a la doctrina pavloviana de los reflejos condicionados como un sistema propicio a la explicación materialista de los fenómenos psíquicos.

Los partidarios de la psicología biológica en todas sus derivaciones gustan de llamarla cientifica, pues propugna el estudio experimental de los hechos psicológicos, como si se tratara de cuestiones netamente materiales y la única vía de acceso científico al psiquismo estuviera constituida por las pruebas de laboratorio que marchan acordes a los procedimentos de la biofísicoquímica, de la cual depende y en la cual llega a consistir. No obstante, el tono diferencial entre esta psicología científica y las ciencias naturales en las que arraiga, es precisamente la atribución aporética de la conciencia, el reconocimiento de que esta modalidad psicológica, como las demás, admite el correlato insustituible de los fenómenos conscientes. De ahí que la definición propuesta en un principio le sea aplicable en su propio ámbito.

Concluimos, pues, que la psicología biológica o "científica" reconoce la atribución general que señalamos de la psicología como ciencia de la conciencia, desde el momento en que la actividad consciente constituye el punto de referencia autónomo en sus experimentos, el criterio que la salva de trasladarse íntegramente a las ciencias naturales _biología, física y química, con su denominador común matemático-, pero la circunscribe al aspecto material del psiquismo, cifrado en el hecho innegable de que la acción consciente se produce en la persona, que es un ente psicofísico y encarna la realidad material del ser humano.

Nosotros estamos de acuerdo en que la psicología biológica amerita la denominación de científica, pero no creemos que esa atribución deba conferírsele en exclusiva, pues igualmente científicas son las otras corrientes, como la psicología básica, la analítica y la social; aun la parapsicología e inclusive la filosófica, en su momento. En cada caso, la cientificidad se ampara en la experiencia individual del psiquismo y en el método sistemático que se prosigue para su explicación; cada una de las escuelas que examinamos merecen el calificativo de cientificas porque arbitran los argumentos y pruebas conducentes a la demostración de sus teorías, mediante una secuencia estructural que configura la metodología científica, específica y auténtica en cada caso.

El monopolio que pretenden implantar quienes consideran como científica únicamente a la psicología biológica, se apoya en los experimentos de laboratorio, los cuales se efectúen con toda precisión y llegan a nivel de mediciones exactas; pero recordemos que la exactitud no es el atributo más destacado de la conciencia y muchas veces ni siquiera de las ciencias; no hay 
razón para dogmatizar que toda ciencia deba ser rigurosamente exacta; quizá los datos cuantitativos resulten adecuados en su campo y en una problemática que corresponde a la fisiología, más que a la psicologia propiamente dicha, aunque los materialistas se afanan por explicar el funcionamiento fisiológico de la conciencia y en ocasiones pertenecen con más derecho a la biofisiología que a la psicología propiamente dicha.

Por todo ello, la posición empírica del biologismo no riñe con la definición clásica que considera a la psicología como ciencia de la conciencia, aunque manifiesta un cierto antagonismo contra el concepto tradicional que la maneja en forma abstracta, como si estuviera separada del proceso biológico que la determina realmente, aunque no de manera total ni absoluta.

\section{d) La psicologia analítica}

La cuarta de las grandes corrientes que señalamos como integrantes de la psicología, es quizá la que más se ha desarrollado en los últimos tiempos: la psicología analítica, cuyo fundador, Sigmund Freud, realizó la primera investigación sistemática para demostrar la existencia de los mecanismos interconscientes sobre los cuales fincó definitivamente el cimiento de esta nueva orientación. El punto de partida en su sistema es un análisis del inconsciente, y su tratamiento dinámico le pone en relación a los complejos problemas de la interconciencia, revelando el gran número de motivaciones que habían permanecido ignotas en la historia anterior a la era freudiana.

Es un lugar común afirmar que Freud es el "descubridor del inconsciente" y aunque esta afirmación es virtualmente cierta, antes de él se había hablado en forma indirecta de los fenómenos "ocultos" de la personalidad, o sean los que escapan parcial o totalmente al nivel epidérmico de la conciencia propiamente dicha; algunos psicólogos anteriores a Freud habían señalado la existencia de una importante área de la personalidad, representada por el inconsciente, pero fue el médico de Viena quien llevó a cabo la primera exploración profunda, incidiendo en los múltiples aspectos de la personalidad con los problemas que reviste la afirmación del inconsciente como una expresión, y al mismo tiempo explicación, de la conducta humana. Con ello asume el inconsciente, como le llamamos nosotros, el interconsciente, una trascendental e insustituible importancia en el estudio analítico del psiquismo.

Los complejos problemas que conlleva la acción del interconsciente en la conducta, fueron explorados por Freud y sus discípulos en el terreno de la psicopatologia, mediante la observación de personas que, por padecer algún desequilibrio en su conducta, se consideran enfermos o anormales. El descubrimiento freudiano consistió en demostrar que todos, en mayor o menor medida, tenemos anormalidades $y$, aunque no seamos enfermos propiamente 
dichos, sufrimos constantemente el embate de numerosas patologías que se traducen en síntomas y símbolos de la vida cotidiana, algunos de los cuales, aparentemente inocuos, tienen sin embargo un profundo significado que solía quedar inadvertido en sus verdaderas causas y sus trascendentales efectos. La doctrina freudiana es una comprobación fidedigna de que el influjo del inconsciente no es pasivo ni pequeño, como se había creído con anterioridad; las motivaciones inconscientes aportan quizá el más importante acervo de experiencias causales que ejercen una decisiva acción en la personalidad.

El inconsciente está representado también en la organización biológica de la especie; de acuerdo a la convicción de Freud y posteriormente de Jung, la estructura bionatural, ya sea ontogénica-individual o filogénica-colectiva, desempeña un papel muy importante en la conducta de los individuos y los pueblos. La explicación analítica sobre la gran existencia de los institutos representa sin lugar a dudas la gran revolución de la psicología moderna; en ella se observa la dotación hereditaria con la cual nace el individuo y se identifica con el género, la especie y subespecie de la clasificación biológica, hasta llegar a la herencia personal que se comprueba de padres a hijos y adquiere en el hombre mayor diferenciación que en ningún otro género de la naturaleza. La presencia y acción de los instintos ha dado origen a la disputa de hasta qué punto son un producto de la herencia biológica y hasta qué otro derivan de las influencias que el medio traspersonal ejerce directa e indirectamente, a partir del nacimiento o quizá antes de él.

El carácter analítico de esta psicología obedece a su método, consistente en analizar la experiencia en función de la organización psíquica, y recíprocamente; distingue en forma sistemática sus componentes primarios, para lo cual se requiere ir más allá de las manifestaciones aparentes de la personalidad e ingresar en sus dimensiones profundas. De ahí el calificativo de analitica que recibe esta psicología, como también el método profundo que se emplea para justificarlo, aunque universalmente sigue reconocido con el nombre que le otorgó su fundador: psicoanálisis, vale decir, análisis psicológico. También a Freud se debe otra designación que considera al sistema como psicología profunda, nombre y concepto ya acreditados en esta importantísima dirección de la psicología moderna.

El logro más destacado del sistema analítico radica en el análisis del inconsciente, iniciado por Freud y continuado por un gran número de prosélitos. El acuerdo existente en todos ellos — por encima de sus amplias discrepancias- radica en aceptar a la organización psicológica como una estructura dinámica, integrada por dos estratos fundamentales que corresponden al inconsciente, o sea el área profunda de la personalidad, cuya acción es determinante sobre la conciencia propiamente dicha, la cual aflora en la conducta con un vasto conjunto de funciones que configuran la deliberación del existir. Conciencia es tanto como deliberación consciente y, en tal aspecto, 
asume una importancia capital para entender y dirigir la vida con un sentido normal que significa no sólo el vivir equilibrado, sino también creativo.

El estrato de la personalidad que reconoce la psicología analítica en indisoluble vinculación con los anteriores, corresponde a lo que llama Freud el superyó, o sea una especie de supraconciencia donde se incuban las normas de conducta y los ideales que se consideran valiosos para orientar el comportamiento. También en este caso hay un superyó individual y otro colectivo; están indisolublemente ligados y se influyen de manera inexorable en todos los actos de la vida. El superyó colectivo determina al individual, y recíprocamente, éste se modifica de manera continua ante el imperio de las reacciones individuales que van conformándose en la mentalidad gregaria, hasta representar la suma de ideales o normas que regulan la existencia social.

En los países civilizados, el superyó se traduce a códigos legales y costumbres de la sociedad, que expresan casi siempre las aspiraciones del convivio, aunque el transcurso del tiempo las estratifica y rezaga ante la evolución individual que reacciona ágilmente por los cambios impresos a la dinámica interpsíquica en el transcurso de la experiencia cotidiana. Determinadas condiciones sociológicas generalizan esta sensibilidad individual y la tornan colectiva hasta que, después de cierto tiempo, se impone una nueva exigencia para cambiar las normas vigentes; entonces se producen las alteraciones en las reglas de conducta social, ya sean públicas o privadas, y con ello se altera la fisonomía de la sociedad misma. Las mutaciones en el inconsciente colectivo aparecen constantemente por efecto de las múltiples y reiteradas acciones individuales que así lo determinan.

He aquí pues, en síntesis, la teoría que alimenta a las posturas de la psicología analítica y que pueden reducirse a un solo concepto: la dinámica interconsciente. Esta dinámica es insoslayable ante los ojos del psicólogo moderno; omitirla sería falsear la estructura primaria de la actividad y equivaldría a negar la realidad auténtica en la cual se funda el desarrollo individual y colectivo de la personalidad.

\section{e) La psicología social}

La quinta de las grandes direcciones que examinamos en la psicología, cuenta con un tema básico que adquiere cada vez mayor importancia. Se trata de la psicologia social. El tema corresponde a las relaciones de sensibilidad y conducta que se establecen entre individuo y sociedad.

Como su nombre lo indica, esta disciplina maneja el problema psicológico a nivel de organización colectiva, cuyas formas de comportamiento revelan la existencia variable y dinámica de una conciencia social. El problema adquiere gran complejidad porque se maneja a través de la estructura conjunta de las ciencias sociales $y$, en cierto modo, es un problema menos asequible que el individual. 
La referencia específica más importante en la psicología de la sociedad es la concerniente al método; sabemos que la psicología individual cuenta con el valioso método introspectivo, que permite la consulta inmediata del $Y o$ para averiguar lo que sucede en el psiquismo. La introspección observa directamente los acontecimientos en la interioridad del psiquismo y en tal sentido es un método irremplazable; capta la experiencia directa de la vida individual y extrae del sujeto las conclusiones que corresponden en cada caso como una inducción genérica que funciona a título de norma explicativa.

Pero la introspección directa es imposible en la psicologia social; cada uno de nosotros es un individuo y no puede inferir de sus experiencias personales lo que sucede colectivamente en el convivio; por otra parte, aunque existe un denominador común muy influyente en el comportamiento, las diferencias individuales en medio de los parámetros psicosociales son muy agudas y podría concluirse con fundamento que son mayores las diferencias que las semejanzas entre los miembros de una sociedad. Mientras más evolucionada sea ésta, los individuos acusarán mayores divergencias aunque pertenezcan a una misma colectividad, y también en la confrontación de una sociedad con otra. Mientras más rudimentarios sean los términos del convivio, las semejanzas serían mayores entre los individuos y los pueblos.

La psicología social recurre en sus investigaciones al método estadístico e infiere las reglas de conducta colectiva conforme a los cánones de las ciencias naturales, básicamente la ley de causalidad, porque en las circunstancias de mayor conjunción interpersonal, el hombre parece comportarse como efecto de una causa ajena, más que como causa de sus propios efectos, o lo que equivale, es mayor el determinante ajeno que el de la propia deliberación. Cuando transitamos de la psicología singular a la psicología en plural, se produce una transformación de la metodología, tanto en el punto de partida, o sea el campo de observación aporética, como en el método para obtener las conclusiones que integran su doctrina.

El ascenso que debe producir la psicología social en cumplimiento de su necesidad cientifica, tiene como punto de partida las observaciones singulares en los diferentes estratos y grupos del comportamiento masivo, pretendiendo llegar a normas generales que puedan explicarlo como una totalidad orgánica. La pesquisa no se detiene en el plano de las observaciones concretas; obtener normas o leyes que expongan las causas del comportamiento fenoménico, en el desideratum de toda ciencia. La psicología social pregunta qué normas, reglas o leyes rigen el comportamiento de los pueblos, y qué relación puede establecerse entre la conducta individual y la colectiva.

Ambas cuestiones requieren un amplio volumen de trabajos en su tratamiento; el problema se agudiza porque la conducta de los grupos se ubica en la evolución histórica, con su inherente dimensión de singularidad social; no existen dos sociedades o formas iguales de comportamiento psicológico. 
Cada época y cada lugar señalan un caso específico de conducta social que puede y debe ser investigada atendiendo a los caracteres singulares que presentan cada núcleo humano en su condición histórica de colectividad única e irrepetible.

Este hecho reafirma el carácter de ciencia que tiene la psicología social y la complejidad que adquiere cuando reune tal cantidad de factores sociológicos, económicos, políticos, antropológicos e históricos, indispensables para resolver su problema; por momentos parecería que esta disciplina se traslada por completo al campo de las ciencias sociales, en cuyo caso el núcleo de los determinantes aporéticos de la conducta colectiva se encontraría en el grupo de estas ciencias, mientras la fenomenicidad psicológica ocuparía un lugar periférico, esto es, secundario. Empero, la tónica de la psicología social sigue siendo propiamente psicológica, porque las leyes determinantes de sus fenómenos son en primer término de índole psíquica, pero los canales de influencia son tan amplios que el caudal de sus actividades podría en cualquier momento desbordarse a través de ellos. En cierto modo ha sucedido así en el tipo de colectividades que acentúan el denominador común social, dejando en segundo término el mediatizado fuero de los individuos. Por ello es muy distinto el comportamiento de las sociedades con ideología colectivista a las que mantienen una ideología acendradamente individualista.

Todas las sociedades, por históricamente producidas, adquieren un perfil sui generis: cada una ostenta de manera peculiar los inconfundibles rasgos de su individualidad; a pesar de ello, el problema de la psicología social subsiste en los términos de generalidad que hemos dicho y recibe un poderoso auxilio de todas las ciencias sociales: economía, política, antropología, historia, axiología y desde luego la sociología misma, que coadyuva eficazmente al desempeño de una tarea que podríamos definir en las cuatro siguientes preguntas:

a) ¿En qué condiciones ambientales puede explicarse el comportamiento colectivo?

b) ¿Qué relación existe entre la conciencia individual y la conciencia social?

c) ¿Qué elementos permanentes caracterizan a través del tiempo a la conducta de los pueblos?

d) ¿De qué manera se escinde el psiquismo social en psiquismo grupal y cómo se determinan sus formas de conducta?

En aras de este cuádruple problema los psicólogos desvían su atención del psiquismo individual, que tradicionalmente les atrae, a la entidad superlativa de la sociedad en la cual conviven. Quienes cifran el estudio psicológico en la realidad social, aceptan a la conciencia supraindividual como punto de partida en sus consideraciones sobre la sociopsicología, admitiendo la necesaria referencia al reconocimiento múltiple de la acción inḍividual, que se 
traduce finalmente en la relativa homogeneidad de la conciencia colectiva. Por ello, los estudiosos del problema informan que existe una conciencia social, en ocasiones contrapuesta a la individual, cuyos caracteres se exhiben con amplificada dimensión en los fenómenos histórico-dialécticos que encuentran una referencia aporética y metodológica de orden colectivo.

\section{f) La psicologia parafisica}

Llegamos a la última de las modalidades en que se manifiesta el estudio direccional de la psicología. Se trata de la corriente o dirección conocida como parapsicologia y que nosotros llamamos también psicologia parafisica o parapática. Esta disciplina se ocupa de acometer la más nueva o quizá la más vieja de sus tareas: el estudio de cierto tipo de fenómenos que por raros o extraños se habían tenido hasta ahora como sobrenaturales y, por lo mismo, cientificamente inexplicables.

Obvio es que la palabra "sobrenatural" resulta muy controvertible y de hecho se ha discutido bastante. Nosotros la mencionamos por ser la acepción habitual, aplicada a esta suerte de fenómenos; pero de inmediato se impone una crítica: lo sobrenatural no existe. Interesa destacar, en todo caso, la existencia de ciertos fenómenos psicológicos o parapsicológicos, páticos o parapáticos que, debido a su extrañeza, resultan de difícil explicación, por cuyo motivo se han designado comúnmente como sobrenaturales.

Para citar algunos mencionemos, por ejemplo, los casos de hipnotismo, clarividencia, telepatía, telaudiencia, premonición, desdoblamiento, catalepsia, levitación, mediumnidad y muchos más que figuran en el vasto catálogo de los hechos casi siempre temidos, aunque muchas veces buscados por el común de las gentes, como si fueran sobrenaturales; temidos, porque se les tiene como una manifestación de lo sobrenatural y se interpretan como alguna especie de comunicación o mensaje del "más allá".

Todos ellos integran un abundante repertorio de acontecimientos poco comunes en torno a los cuales se realizan ahora multitud de experimentos controlados que tienden a explicarlos como hechos reales y naturales, susceptibles de conocimiento científico e inclusive se les procura una demostración de acuerdo a los cánones estrictos de la metodología rigurosa; con ello se abre en esta época la puerta de la comprensión racional no sólo para reconocer la existencia de dichos fenómenos, sino también para admitir la posibilidad de explicarlos y producirlos sistemáticamente.

El corolario que deriva de esta clase de experimentos señala, como hemos dicho, que los sucesos observados constituyen manifestaciones anormales del psiquismo, aunque de ninguna manera sobrenaturales. No se observan con frecuencia en todos los sujetos, por lo cual son anormales, pero de ningún modo indica esto que sean sobrenaturales, por la sencilla razón de que lo 
sobrenatural no existe. Aclaremos de una vez por todas: desde el momento en que algo existe, es natural, por más extraño que parezca a nuestra observación común. Tal es el caso de los fenómenos parapsicológicos, que son extraños pero naturales, aunque raros y casi siempre anormales. Se les considera enfermizos o patológicos, de donde la denominación que también les conferimos, como páticos o parapáticos, por decir patológicos o patógenos similares.

La razón del vocablo parapsicología, con el cual se designa a esta nueva y discutida ciencia, es que se la ubica al lado aunque fuera de la psicología, no propiamente como parte de ella; esto es lo que significa el vocablo: parapsicología. Es en cierto modo, casi una psicología, está junto a la psicología, pero no es la psicología misma. Nosotros la llamaremos psicologia parafísica porque se la entiende como una rama inherente a la psicología, pero en vista de que sus fenómenos son raros o extraños, no los más frecuentes ni normales, se les ubica más allá de los hechos comunes del psiquismo sensorial, que se entienden propiamente como sucesos físicos o naturales. De ahí, pues, el adjetivo de parafísica que otorgamos a esta rama de la psicología: parapsicologia o psicología parafísica.

Obviamente, el concepto de lo físico en psicología es muy controvertible pues abarca desde las reacciones computables por medio de aparatos en el laboratorio conductivo, hasta manifestaciones tan sutiles y recónditas que no se han logrado manejar a la manera positiva en la experimentación de gabinete, pero son objeto de una determinación experiencial cada vez más científica y precisa, que tiende a asimilarlos en el canon demostrativo de una empiriología psicológica. Es un distingo parecido al que hay, mutatis mutandis, entre las reacciones endócrinas que acompañan a un arrebato emocional y las descargas eléctricas o las ondas electromagnéticas que genera el cerebro al ocurrir el acto del pensamiento.

La dificultad que ha existido y sigue existiendo para el estudio científico de los fenómenos parapsicológicos estriba fundamentalmente en que, tratándose de sucesos raros o anormales, se presentan en un número muy reducido de personas $y$, comparativamente hablando, vienen a ser en alguna forma ultrafenoménicos, por lo cual su rareza y también la falta de dominio experimental para controlarlos queda al margen de la normatividad científica que debe ser teóricamente inexcepcional y causal, es decir, que los fenómenos puedan producirse siempre que se quiera, en las condiciones establecidas por la observación y con la misma regularidad objetiva que existe en la relación de causa a efecto.

Por otra parte, los fenómenos parapáticos se asocian con gran frecuencia a la idea de lo sobrenatural y, con ella, a la imagen de la muerte y el más allá de lo celestial y lo infernal, del pecado y la perdición. $O$, por el contrario, se busca en ellos la bienaventuranza eterna mediante el perfeccionamiento 
del hombre y la purificación del alma. Todo ello riñe, en principio, con la seriedad inherente a la investigación científica, pero justo es decir que cada día se despeja más la bruma de superstición, la aureola de magia que aún envuelve a la fenomenología parapática y se logra que dichos fenómenos se produzcan con mayor regularidad, que su génesis obedezca a la experimentación científica, desterrando con ello la superestructura mágica y mitológica que casi siempre la ha rodeado.

Dentro de ese carácter anormal puede un hecho ser más o menos frecuente $o$ infrecuente, acercarse o alejarse de las formas comunes del psiquismo; los fenómenos parapsíquicos se alejan bastante de la normalidad y son poco frecuentes en comparación con las manifestaciones normales del comportamiento, aunque ello no autoriza de ningún modo a considerarlos sobrenaturales; simplemente son raros o extraordinarios, pero son casos reales que la ciencia estudia cada día con más profundo interés, buscando la comprensión de un mundo que hasta ahora se había tenido por inaccesible a la investigación científica.

La existencia de tales fenómenos se reconoce desde la antigüedad; en número incontable los registran hace muchos siglos la historia, la tradición, el mito, la leyenda y la fábula; figuran en toda clase de anécdotas y relatos que se han tomado casi siempre como supercherías. Algunas referencias que se encuentran en las religiones sobre supuestos acontecimientos "sobrenaturales", que comúnmente se denominan "milagros", bien pudieran corresponder a sucesos reales aunque anormales, de apariencia sobrenatural, cuya deficiente interpretación ha corrido casi siempre a cargo de la desbordada fantaśa del pueblo, generalmente inculto, que los consagra como "milagros" ante la imposibilidad de comprenderlos racionalmente.

El rechazo de los sucesos parafísicos ha perdurado en la ciencia oficial durante mucho tiempo; hasta hace unos cuantos años la actitud más común consistía llanamente en reprobar cualquier mención de tales fenómenos, condenando por ignorante o supersticioso a quien los aceptara o quisiera discutir sobre ellos. La ciencia académica fue tradicionalmente refractaria a lo que considerara un desvío de la estricta línea delimitada por la experiencia de laboratorio; se opuso a trascender el reducido alcance de la experimentación, sujeta al criterio de gabinete esgrimido muy rigurosamente por los severos académicos.

\section{La psicología sincrética}

Hasta aquí, la exposición breve y superficial de las grandes corrientes en que se escinden las doctrinas de la psicología; la clasificación que hemos propuesto de psicología filosófica, básica, biológica, analítica, social y parafísica, permite distinguir los parámetros determinantes en la indoctrinación 
de esta ciencia, correspondiendo a sendos niveles fenoménicos en los que se generan sus problemas.

La clasificación elaborada por nosotros es también el umbral de la que denominamos psicología sincrética, que bien puede entenderse como sincretismo psicológico, y no constituye una vertiente específica, además de las anteriores, sino la incorporación unitaria de todas en el sistema de síntesis donde deberán acogerse todas las teorías que pertenecen a las vertientes diferenciales de acuerdo a la función que desempeña cada una en concordancia con el agente psicológico respectivo: las hipótesis primarias en la psicología filosófica, las facultades generales en la psicología básica, el mecanismo biofísico en la psicología biológica, la acción interconsciente en la psiología analítica, la relación individuo-colectividad en la psicología social y los fenómenos metaconscientes en la psicología parafísica o parapsicología.

El interrogante que se presenta en la última etapa de nuestras consideraciones será el siguiente: ¿̇en qué forma y medida es posible coordinar los agentes psicológicos y sus respectivas escuelas o doctrinas, en un sistema conjunto de psicología sincrética?

Subrayemos: el concepto de sincretismo equivale al establecimiento de la unidad sistemática y estructural que vincula una serie de opiniones divergentes y las completa en virtud de sus funciones implicantes o integrativas; en virtud de esta unidad se exhibe el decurso evolutivo de la psicología en paralelo a la estructura integral y unitaria del psiquismo.

Esta conjunción epistémica florece actualmente en todo el campo del saber. Sin duda están operándose transformaciones singulares en el conocimiento del ser humano, concernientes todas ellas al concepto de la psicología como teoría y como práctica, individual y colectiva, en lo mental y lo somático. Según las viejas doctrinas que se vinculan a las nuevas, el sincretismo psicológico $\mathrm{y}$, más aún, antropológico, es la única solución para recapitular el enorme volumen de los conocimientos sobre el hombre, ante la imposibilidad de que aisladamente se les pueda comprender en su abismal complejidad. Para obtener la síntesis de tales conocimientos será necesario conjeturar paralelamente los aspectos, sintetizar los problemas y reunir las posibilidades del hombre. Ya no es posible entenderlo aislada o parcialmente; las leyes más profundas que explican sus manifestaciones de conducta se encuentran integralmente más allá de cada una en lo particular, sobre un estrato fenoménico y epistémico que recoge las fórmulas singulares en aras de una búsqueda universal.

Así explicamos también el propósito que hemos perseguido en este ensayo; el sincretismo psicológico encuentra un amplio horizonte de posibilidades para desarrollarse con la evolución y comprensión de lo humano en la psicología y la parapsicología, en la antropología y la sociología, en todo el campo de las ciencias del hombre y de la naturaleza. mediante el descubrimiento de 
insospechadas facultades e ignotos mecanismos que probablemente revelarán en un próximo futuro los secretos más recónditos de la acción psíquica y los elementos más fecundos de la personalidad.

El cambio radical que debe operarse en la ciencia psicológica provendrá en gran parte de la aceptación oficial de la que hemos llamado paraconciencia y cuyos fenómenos corresponden al nivel del análisis pasapsíquico. Aunque por ahora el estudio oficial de la psicologia se encuentra separado en algunos círculos profesionales de los experimentos parapsicológicos, por una barrera - hoy es sólo una barrera, antes era un abismo inzanjable - en otros se les acepta y se les cultiva con creciente entusiasmo; la distancia entre psicología y parapsicología se acorta cada vez más y la barrera se esfuma ante los descubrimientos del psiquismo parafísico que, a pesar de todo, revelan determinados aspectos naturales del ser humano que hasta ahora habían sido incomprendidos; son quizá los más profundos, extraños o extraordinarios si se quiere, anormales, posiblemente, pero a fin de cuentas fenómenos naturales, no tan sólo porque suceden en la naturaleza sino porque se explican en función de leyes naturales y cientificas.

En tal virtud es posible integrar el gran sistema sincrético de la psicología, teniendo en cuenta el desarrollo de las facultades humanas en la extensa gama de sus niveles integrativos, desde loß̣ más elementales hasta los más complejos, de los más antiguos a los más modernos, partiendo de los más rudimentarios a los más elevados. En tan applio horizonte se advierte, por una parte, la creciente complejidad que exhiḅe el análisis de las facultades, de los organismos y las funciones del psiquismo y, por otra, la integración paulatina de los puntos de vista que aplican la psicología, y genéricamente las ciencias antropológicas, al estudio del ser humano.

Esta complejidad acrecienta y enriquece el sistema que configuran las ciencias encargadas de estudiar al hombre. En tal sistema la psicología ocupa una parte importante, pero sólo una; con ella existen y coexisten otras disciplinas que tienen un sentido autónomo y delimitan sus respectivas jurisdicciones, contribuyendo a que la ciencia psicológica asuma plenamente la suya. Cuando se contemplan en conjunto, surge la conclusión de que para entender al hombre no es posible permanecer indefinidamente en el ámbito de una sola disciplina, cualquiera que sea; si intentamos explicar con fidelidad el sentido de la existencia no bastará la psicología, ni siquiera en todas sus corrientes, para abarcar íntegramente sus variadas dimensiones; ella misma no puede justificarse sin los diversos puntos de referencia que le confieren las disciplinas colindantes.

De esta suerte se refrenda la función teleológica normativa de la psicología cuando es dirigida no sólo al conocimiento sino también y quizá fundamentalmente a la formación del hombre, porque la finalidad de esta ciencia no es únicamente la explicación del ser humano, sino la postulación del 
- debe ser teleológico y normativo, individual y colectivo, que no se agota en la explicación teorética asertórica normal. La psicología contiene la referencia epistémica central para que la postulación de lo humano sea factible y prosiga sobre bases científicas a fin de que se realice y no permanezca simplemente como una idea utópica del hombre o noción abstracta de su conducta.

Miguel Bueno

INSTITUTO dE INVESTIGACIONES FiLOSÓficas

Universidad Nacional Autónoma de México 